\title{
Usage of Fiber-Reinforced Resin Instruments in Interproximal Surfaces
}

\author{
Deniz C. Can-Karabulut ${ }^{a}$ \\ Perihan Ozyurt ${ }^{\text {b }}$ \\ Ayhan Gurbuz ${ }^{c}$ \\ Abdulkadir Gullu
}

\begin{abstract}
Objectives: The aim of this study was to investigate the effects of fiber-reinforced resin burs on the surface roughness of a nanofilled composite.

Methods: Average surface roughness values $(\mathrm{Ra}, \mu \mathrm{m})$ were measured using a surface profilometer and surface textures after finishing procedures were evaluated using a scanning electron microscope (SEM). Thirty cylindrical specimens were prepared using sectional teflon molds. A nanofilled composite was chosen. After the preparation specimens were divided into three subgroups randomly. After profilometric measurements, representative samples of the mentioned finishing procedures were selected and SEM analyses were carried out.

Results: Mylar strip group was statistically different from the other two groups $(P<.05)$. The smoothest surfaces occurred when composite resin samples were light cured against the strips. On the other hand there was no statistical difference between fiber-reinforced resin burs and Sof-Lex discs ( $P>$.05). For fiber-reinforced resin burs scratches and pitting which may be due to plucking of the filler particles during finishing were observed on the surface topography of the composite resin material. On the other hand, for the Sof-Lex discs although scratches were noticed on the surface topography, no pitting was observed.

Conclusions: Fiber-reinforced resin burs can be preferred for the grinding of composite surplus in interproximal surfaces, where the use of Sof-Lex discs can be harmful to soft tissues. (Eur J Dent 2008;2:96-1011
\end{abstract}

Key words: Fiber-reinforced resin burs; Nanofilled composite; SEM; Sof-Lex discs; Surface roughness.

\section{INTRODUCTION}

Proper finishing of restorations is desirable both for esthetic considerations and for oral health. ${ }^{1}$ Restoration finish, surface roughness and integrity can influence plaque retention, periodontal disease, recurrent decay and staining of the resin composite. ${ }^{2-4}$ There are various
$\mathrm{PhD}$, Department of Operative Dentistry, Faculty of Dentistry, Near East University, Mersin, Turkey.

b Assoc. Prof., Department of Operative Dentistry, Faculty of Dentistry, University of Ankara, Ankara, Turkey.

Prof., Department of Prosthetic Dentistry, Faculty of Dentistry, University of Ankara, Ankara, Turkey.

\footnotetext{
d Assoc. Prof., Department of Engine Education, Faculty of Technical Education, University of Gazi, Ankara, Turkey.

Corresponding author: Dr. C. Deniz Can-Karabulut Department of Operative Dentistry,Faculty of Dentistry, Near East University, Mersin, Turkey. Phone:+90 39268020 30/2618 Fax: +90 3926802025 E-mail: cdenizcankdayahoo.com
} 
procedures commonly used in dental practice for the finishing of composite surfaces like aluminum oxide paste, diamond paste, rubber polishers, diamond polishing burs, tungsten carbide burs for producing a smooth surface. ${ }^{2,5}$ Flexible discs appear to be reliable finishing instruments for the most composite materials. ${ }^{6}$ Studies reported that Sof-Lex discs showed areas with a smooth and homogenous final restoration surface. ${ }^{5,7}$ But although Sof-Lex discs are reliable devices for the finishing of composites, these abrasive discs can harm soft tissues especially when they are used in interproximal surfaces.

New burs out of composite material, a resin reinforced by zircon-rich glass fiber, have been introduced for various uses. Their indication relating operative dentistry, mentioned by the manufacturer, is grinding of composite surplus between teeth without being harmful to enamel where any other rotary instrument would likely be. According to the manufacturer, operations are performed efficiently without any harm to the soft tissues. They are made up of a resin which is reinforced by zircon-rich fiberglass which is $14 \mu \mathrm{m}$ in diameter and are designed to remove cement, stains and colored coatings gently from the surface of the enamel. They do not abrade tooth enamel or ceramic and only chip cement, dentin and filling composites and that this type of fiberglass unlike ordinary fiberglass does not split up into minuscule fibrils which are extremely irritating to the skin and mucous membrane. Instead of splitting they are suggested to break or fragmented into particles which are always longer than $5 \mu \mathrm{m}$. Therefore they are suggested to be not breathable. Their action of mechanism is told to be with the fiber sections; fiber sections with abrasive power, split up into small fragments when they act on a hard surface. At the same while their resin matrix is used up new sections of fibers are exposed so these burs are told to be self-sharpening whilst continuously maintaining their abrasive power. They are latchhead burs which can be used with a contraangle and water spray which all practitioners have in their dental office, and require no special device. Practitioners can subsequently use them in accessible places, for their abrasive power remains intact even if the initial shape is lost.

There are studies referring the usage of these instruments. ${ }^{8,9}$ Liebrecht and Finger ${ }^{8}$ reported that the crucial advantage of these fiber instruments was the good access to narrow undercut areas and interproximal spaces. Finger et $\mathrm{al}^{9}$ also reported that enamel surface stain removal with these instruments was effective and very little invasive. No side effects to soft tissues had been reported in both of these studies. According to these studies these instruments were very effective in surface stain removal of enamel and for removal of resin remnants from dental implant and ceramic crown surfaces in interproximal surfaces. ${ }^{8,9}$

It was thought that these counted properties; being harmless to soft tissues and enamel are very appealing for clinic applications and it was aimed to study whether these burs have any detrimental effects for composite surfaces in vitro. For this purpose surface roughness values of a nanofilled composite resin restorative material after finishing with a series of Sof-Lex discs and fiber-reinforced resin burs were compared.

\section{MATERIALS AND METHODS}

Thirty cylindrical specimens with a height of $2 \mathrm{~mm}$ and a diameter of $8 \mathrm{~mm}$ were prepared in sectional teflon molds. Molds were slightly overfilled with a nanofilled composite resin material (Grandio, Voco, Cuxhaven, Germany) by using a plastic instrument, covered with mylar matrix strips, placed between two glass slides and cured for $40 \mathrm{~s}$ with a visible light curing unit (Hilux, Benlioglu Dental A.S., Ankara, Turkeyl from both sides. The curing light guide of the light curing unit was moved on both sides of the specimens for an additional 20 seconds after removing the strips and glass slides. Light intensity was monitored with the Hilux curing radiometer (Curing Radiometer, Model 100, Demetron/Kerr Corporation, Danbury, USA) prior to the experiment.

Specimens were divided into three subgroups randomly and stored in distilled water for $24 \mathrm{~h}$ at $37^{\circ} \mathrm{C}$ prior to finishing procedures. To minimize variability, specimens were finished by a single investigator according to the manufacturers' directions using the same contra-angle (approximately $10,000 \mathrm{rpm}$ ). In the first group aluminum oxide Sof-Lex discs (3M, ESPE, St.Paul, USA) were used with water spray at low speed applying slight pressure. Each sample was finished sequentially with coarse, medium, fine and superfine aluminum oxide abrasive discs. All 
four grits were used in sequence for 30 seconds on the composite samples. After each step, all specimens were thoroughly rinsed with water and air dried before the next step. Abrasive discs were changed after each use. In the second group zirconrich fiber-reinforced resin burs (Stainbuster, Carbotech, Ganges, Francel were used. These latch-head burs were used with contra-angle and water spray at slow speed around 10,000 rpm applying slight pressure. Water spray was applied in order to carry away the grinding debris, cleaning up the working field and so enhance the visibility and the control. In the third group no procedure was applied additional to Mylar strips.

After all these procedures, specimens were thoroughly rinsed with water and allowed to dry for $24 \mathrm{~h}$ before measurement of average surface roughness ( $R a$ ) values in micrometers. The average surface roughnesses $(R a, \mu m)$ of the specimens were measured with the Mitutoyo Surftest-211 Surface Roughness tester (Surftest 211, Mitutoyo, Tokyo, Japan) by a second evaluator who was blind to the finishing procedures. All specimens were tested using a planar motion. The cut-off value for surface roughness was 0.8 $\mathrm{mm}$ and the traversing distance of the stylus was $4.0 \mathrm{~mm}$. The radius of the tracing diamond tip was $5 \mu \mathrm{m}$ and measuring force and speed were $4 \mathrm{mN}(0.4 \mathrm{gf})$ and $0.5 \mathrm{~ms}^{-1}$, respectively. A calibration block was used periodically to check the performance of the profilometer. Three measurements in different directions were recorded for ten specimens in each group, mean Ra value was determined for each specimen and an overall Ra was determined for the total sample.

After profilometric measurements, representative samples of the mentioned finishing procedures were selected for SEM (JEOLJSM•6400, Tokyo, Japan) analyses. Specimens were sputter coated with gold with a thickness of approximately $50^{\circ} \mathrm{A}$ in a vacuum evaporator (MED 010, Balzer Union, Balzers, Liechtenstein). Photographs of representative areas of the finished surfaces were taken at $\times 800$ and $\times 2500$ magnifications at an accelerating voltage of 20 kV. Statistical differences were checked by Oneway Analysis of Variance (ANOVA) $(P<.05)$ and when differences were found between groups, Bonferroni test was used to detect specific differences within material groups $(P<.05)$.

\section{RESULTS}

Results reported for average roughness values ( $R$ a) measured in micrometers are shown in Table 1. The average Ra value of the composites which were light cured against the strips was $0.16 \mu \mathrm{m}$. Sof-Lex discs produced also smooth surfaces for the tested resin composite material. The average Ra value of this group was $0.47 \mu \mathrm{m}$. The average Ra value of the fiber-reinforced resin burs was 0.60 $\mu \mathrm{m}$. Mylar strip group was statistically different from the other two groups $(P<.05)$. The smoothest surfaces occurred when composite resin samples were light cured against the strips. On the other hand, although Sof-Lex discs revealed lower Ra values $(0.47 \mu \mathrm{m})$ when compared with the fiberreinforced resin burs $(0.60 \mu \mathrm{m})$ this difference was not statistically significant ( $P>$.05). Consistent with the profilometric evaluation SEM examination of the representative areas of the finished surfaces which were taken at $x 800$ and $x 2500$ magnifications revealed smoother surfaces for Mylar strip group (Figure 1). For fiber-reinforced resin bursscratches and pitting which may be due to plucking of the filler particles during finishing were observed on the surface topography of the composite resin material consistent with the higher Ra values (Figure 2). On the other hand, for the Sof-Lex discs although scratches were noticed on the surface topography, no pitting was observed (Figure 3 ).

\section{DISCUSSION}

Surface roughness associated with improper finishing can result in plaque accumulation, which compromises the clinical performance of the restoration. ${ }^{2}$ A nanofilled composite resin had been chosen because it had been reported that the use of this kind of resin composite material made with nanoclusters demonstrated the smoothest surfaces after finishing. ${ }^{7}$ Yap et $a^{10}$ also mentioned that composite materials based on nanomer technology were significantly smoother than those based on microfillers. During finishing procedures, filler particles may pluck out leaving voids. ${ }^{1,11}$ Turssi et al ${ }^{12}$ implied that in comparison with minifilled composite, smaller particles might had been sheared off in nanocomposite and smaller voids might had been left on its surface, consequently more even and smoother surfaces had been created. On the other hand, studying the effect of these burs 
on different types of composite resin materials in further studies can be clinically beneficial. New instruments like burs out of a resin reinforced by zircon-rich glass fiber have been introduced for various uses and some of their properties were mentioned in the introduction part. They are introduced as non effective to soft tissues as they slide over them without cutting or grinding. This quality, and the fact that the instrument hardly heats up during use, makes the process virtually pain free, hence its easy acceptance by patients compared to other instruments and methods. But again according to the manufacturer, they act as grinding instruments grinding layer after layer not as cutting burs. Therefore, to be efficient, they must be used at low speed with little pressure. High speed and strong pressure would only lead to faster wear, clog the spaces between the fiber sections and would lessen their abrasive power.

In this study these burs were used for finishing of composite samples and a quantitative analysis of the finishing result was performed with a surface tester. Profilometer is a widespread method in evaluating the surface roughness of composite materials. ${ }^{1,2,10,13-18}$ It provides limited two-dimensional information, but an arithmetic average roughness can be calculated and used to represent various material-finishing surface combinations that assist clinicians in their treatment decisions. ${ }^{1}$ However, according to the same authors, ${ }^{1}$ the complex structure of a surface can not be fully characterized by the use of only surface roughness measurements. Therefore it is not appropriate to draw conclusions on the clinical suitability of a finishing instrument exclusively based on average roughness results. However, in combination with SEM analysis that permits an evaluation on the destructive potential of a finishing tool, more valid predictions of clinical performance can be made. In this study sample surfaces were evaluated also by means of SEM and results of profilometric measurements were largely confirmed by these analyses. But sometimes there can be a difference between the profilometric results and SEM images. According to Tate and Powers, ${ }^{17}$ this difference may be due to surface waviness produced by the treatments. The profilometer detects any waviness within the 0.25 mm cut-off, which would increase the Ra, however SEM can not distinguish overall surface texture. In this study the cut-off value was $0.8 \mathrm{~mm}$. It can be expected that because of this cut-off value there is minimum difference between the profilometric evaluation and SEM analyses. In this study, SEM results revealed that surface irregularities of the materials corresponded to the results obtained using the surface roughness tester. Profilometer and SEM results of the tested materials indicated that Mylar strips provided the smoothest surfaces. This finding is in accordance with St Germain and Meiers. ${ }^{15}$ Also several authors ${ }^{1,14,18,19}$ had mentioned that there was no surface roughness in all resin composites tested against Mylar strips. According to Üçtaşlı et al ${ }^{18}$ and ${ }^{20-22}$ Mylar strip formed surface was the smoothest composite surface produced because of the resin rich layer at the surface.

Another important factor is the usage of an initial finishing technique. Attar ${ }^{23}$ reported usage of a tungsten carbide finishing bur in a rotary motion to simulate initial finishing of the restorative material. But Senawongse and Pongprueksa ${ }^{7}$ had not mentioned usage of an initial finishing procedure in their study. Initial finishing procedures can be helpful in cases where the initial uses of diamond or carbide finishing instruments are required. Because in this study it was aimed to find if these burs had any detrimental effects for composite surfaces an initial finishing procedure was not

Table 1. Mean Ra values and standard deviations for the finishing systems evaluated. ${ }^{\text {a }}$

\begin{tabular}{|c|c|c|c|c|}
\hline Restorative material & Finishing systems & $\mathrm{n}$ & Mean Ra values $(\mu \mathrm{M})$ & $\begin{array}{l}\text { Standard } \\
\text { deviation }\end{array}$ \\
\hline Nanofill composite resin & Sof-Lex discs* & 10 & 0.466 & 0.12 \\
\hline Nanofill composite resin & Fiber-reinforced resin burs* & 10 & 0.603 & 0.17 \\
\hline Nanofill composite resin & Mylar strips & 10 & 0.156 & 0.11 \\
\hline
\end{tabular}

a Mean Ra values ( $\mu \mathrm{M})$ of composite resin surfaces treated with Sof-Lex discs and Fiber-reinforced resin burs were not found significantly different from each other (analysis of variance *: P>.05). 
used but what will happen if fiber-reinforced resin burs are used on surfaces previously treated with diamonds and carbide finishing instruments can be studied in a further study.

SEM examination of the representative areas of the finished surfaces which were taken at $x 800$ and x2500 magnifications revealed smoother surfaces for Mylar strip group consistent with the profilometric evaluation. The exposed filler particles probably indicate resin removal during the finishing procedure. For fiber-reinforced resin burs scratches and pitting which may be due to plucking of the filler particles during finishing were observed on the surface topography of the composite resin material consistent with the higher Ra values. On the other hand, for the SofLex discs although scratches were noticed on the surface topography, no pitting was observed. As it had been mentioned before, SEM evaluation and profilometric results should be evaluated in combination. Although statistical comparison of the $\mathrm{Ra}$ values showed no significant difference between fiber-reinforced resin burs and Sof-Lex discs, according to the results of the SEM evaluation when fiber-reinforced resin burs are used for surface finishing, they can cause resin removal

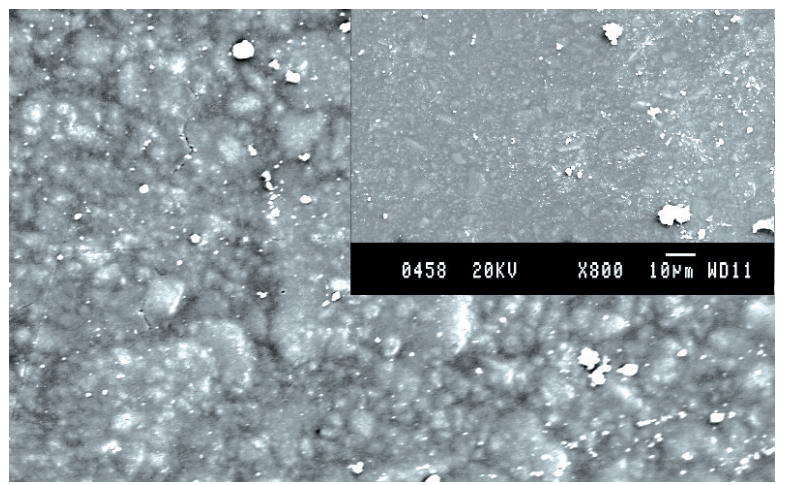

Figure 1. SEM photographs of the composite surfaces at $x 800$ and $\times 2500$ after the application of Mylar Strips.

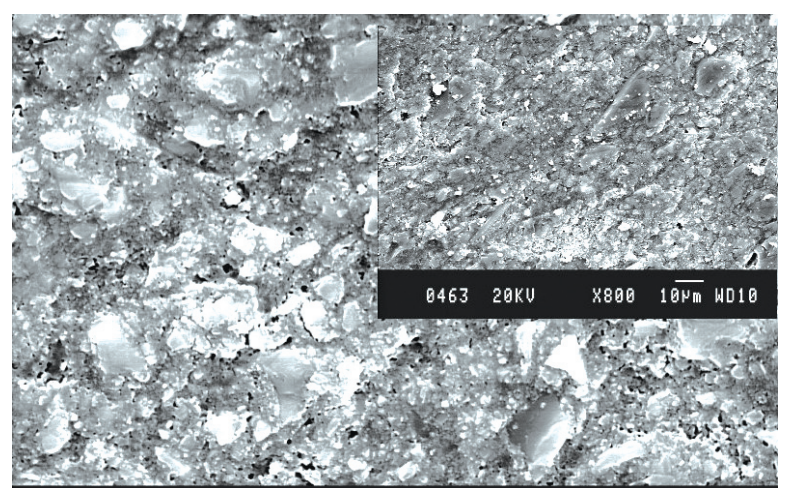

Figure 2. SEM photographs of the composite surfaces at $x 800$ and $\times 2500$ after the application of fiber-reinforced resin burs. or they have a tendency to tear filler particles and leave irregularities to a certain degree. When SEM and profilometric results are taken into account together, from a clinical point of view, these burs can be used for grinding of composite surplus in interproximal surfaces suitable with their indication, but not for the finishing of composite surfaces.

Liebrecht and Finger $^{8}$ reported that the crucial advantage of these fiber instruments was the good access to narrow undercut areas and interproximal spaces. Finger et al $^{9}$ reported that enamel surface stain removal with these instruments was effective and very little invasive. No side effects to soft tissues had been reported in both of these studies. According to these studies these instruments were very effective in surface stain removal of enamel and for removal of resin remnants from titanium-coated implant and all ceramic crown surfaces in interproximal surfaces. ${ }^{8,9}$ In this study it was concluded that although the technique requires the usage of an extra rotating instrument, especially in interproximal surfaces grinding of composite surplus without being harmful to adjacent enamel, soft tissues and composite restoration itself can be very advantageous.

\section{CONCLUSIONS}

Fromaclinical point of view, theadvantageswhich are being not harmful to dental enamel, performing efficiently without giving any harm to soft tissues, requiring no special device, autoclavability, not being fragmented into particles so being not breathable and having a resin matrix which new sections of fibers are exposed so told to be self-sharpening; are taken into account, these fiber-reinforced resin burs can be preferred for the grinding of composite surplus in interproximal surfaces, where the use of Sof-Lex discs can be harmful to soft tissues.

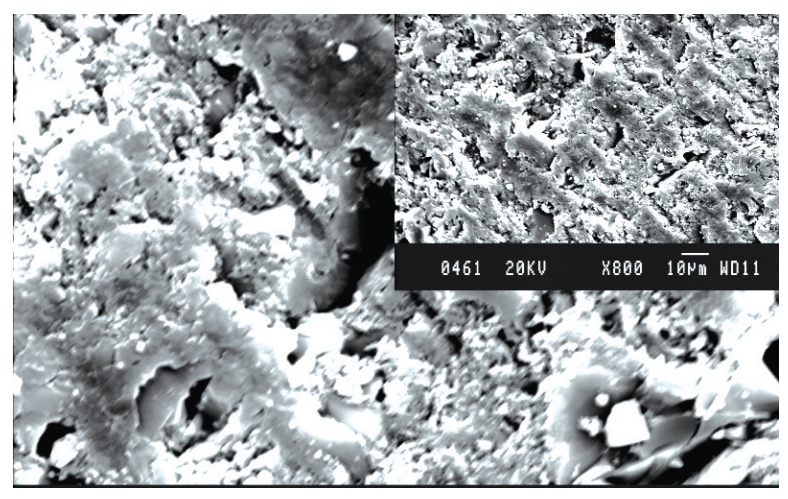

Figure 3. SEM photographs of the composite surfaces at $x 800$ and $\times 2500$ after the application of Sof-Lex discs. 


\section{ACKNOWLEDGEMENT}

This study was performed independently of all manufacturers' commercial promotions as well as the $\mathrm{PhD}$ dissertation of the corresponding author.

\section{REFERENCES}

1. Turkun LS, Turkun M. The effect of one-step polishing system on the surface roughness of three esthetic resin composite materials. Oper Dent 2004;29:203-211.

2. Reis AF, Giannini M, Lovadino JR, Ambrosano GM. Effects of various finishing systems on the surface roughness and staining susceptibility of packable composite resins. Dent Mater 2003;19:12-18.

3. Bollen CM, Lambrechts P, Quirynen M. Comparison of surface roughness of oral hard materials to the threshold surface roughness for bacterial plaque retention: a review of the literature. Dent Mater 1997;13:258-269.

4. Murchison DF, Chan DCN, Cooley RL. Direct anterior restorations. In: Summitt JB, Robbins JW, Schwartz RS, Santos J, eds. Fundamentals of Operative Dentistry. A contemporary approach. 2nd ed. Chicago: Quintessence; 2001:255-259.

5. Radlanski RJ, Best T. New carbide finishing burs to reduce polishing efforts of light-cured restorations. Quintessence Int 2007;38:e555-563.

6. Dietschi D, Spreafico R. Adhesive Metal-Free Restorations. Current concepts for the esthetic treatment of posterior teeth. Chicago: Quintessence 1999:203-212.

7. Senawongse $P$, Pongprueksa $P$. Surface roughness of nanofill and nanohybrid resin composites after polishing and brushing. $J$ Esthet Restor Dent 2007;19:265-273.

8. S. Liebrecht, WJ Finger. Treatment of implant surfaces with rotating fiber-reinforced resin instruments. iadr.confex. com/iadr/2004Hawaii/techprogram/abstract_40921.htm.

9. WJ Finger, WM Ahlstrand, S. Liebrecht. Surface stain removal of enamel with fiber-reinforced resin instruments. iadr.confex.com/iadr/2002SanDiego/techprogram/ abstract_11107.htm.

10. Yap AU, Yap SH, Teo CK, Ng JJ. Comparison of surface finish of new aesthetic restorative materials. Oper Dent 2004:29:100-104

11. Marigo L, Rizzi M, La Torre G, Rumi G. 3-D surface profile analysis: different finishing methods for resin composites. Oper Dent 2001;26:562-568.

12. Turssi CP, Ferracane JL, Serra MC. Abrasive wear of resin composites as related to finishing and polishing procedures. Dent Mater 2005;21:641-648.

13. Borges AB, Marsilio AL, Pagani C, Rodrigues JR. Surface roughness of packable composite resins polished with various systems. $J$ Esthet Restor Dent 2004;16:42-47.
14. Kaplan BA, Goldstein GR, Vijayaraghavan TV, Nelson IK. The effect of three polishing systems on the surface roughness of four hybrid composites: A profilometric and scanning electron microscopy study. J Prosthet Dent 1996;76:34-38.

15. St Germain HA, Meiers JC. Surface roughness of lightactivated glass-ionomer cement restorative materials after finishing. Oper Dent 1996;21:103-109.

16. Tagtekin DA, Yanikoglu FC, Bozkurt FO, Kologlu B, Sur H. Selected characteristics of an Ormocer and a conventional hybrid resin composite. Dent Mater 2004;20:487-497.

17. Tate WH, Powers JM. Surface roughness of composites and hybrid ionomers. Oper Dent 1996;21:53-58.

18. Üçtașlı MB, Bala O, Güllü A. Surface roughness of flowable and packable composite resin materials after finishing with abrasive discs. J Oral Rehabil 2004;31:1197-1202.

19. Baseren M. Surface roughness of nanofill and nanohybrid composite resin and ormocer-based tooth-colored restorative materials after several finishing and polishing procedures. J Biomater Appl 2004;19:121-134.

20. Chung $\mathrm{KH}$. Effects of finishing and polishing procedures on the surface texture of resin composites. Dent Mater 1994;10:325-330

21. Lutz F, Setcos JC, Phillips RW. New finishing instruments for composite resins. JADA 1983;107:575-580.

22. Yap AUJ, Lye KW, Sau CW. Surface characteristics of toothcolored restoratives polished utilizing different polishing systems. Oper Dent 1997;22:260-265.

23. Attar $\mathrm{N}$. The effect of finishing and polishing procedures on the surface roughness of composite resin materials. $J$ Contemp Dent Pract 2007;8:27-35. 